\title{
Effect of Rolling Temperature on Microstructure and Mechanical Properties of a Nb-Mo Microalloyed Medium Mn Steel
}

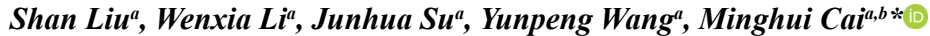 \\ ${ }^{a}$ School of Materials Science and Engineering, Northeastern University, Shenyang 110819, China \\ ${ }^{b}$ Key Laboratory of Lightweight Structural Materials, Liaoning Province, Northeastern University, \\ Shenyang 110819, China
}

Received: November 25, 2018; Revised: May 14, 2019; Accepted: May 19, 2019

\begin{abstract}
Warm rolling of medium Mn steel is a promising technology to meet the needs of vehicle weight reduction and energy conservation while ensuring the safety for passengers. In this study, a novel Nb-Mo microalloyed $6.6 \mathrm{Mn}$ steel was subjected to a series of warm rolling tests at temperatures ranging from 630 to $690{ }^{\circ} \mathrm{C}$, based on the thermodynamic-based prediction of intercritical annealing using a Thermo-Calc software. As a comparison, a conventional multi-stage thermo- mechanical process involving hot rolling, cold rolling and inter-critical annealing was carried out as well. The optimal rolling temperature parameters for warm rolling was explored through tensile tests and the detailed microstructural characterization. The experimental results show that the microstructure and mechanical characteristics strongly depended on the warm rolling temperature. A better combination of UTS and TE products $(\sim 32.0 \mathrm{GPa} \cdot \%)$ was achieved in the $660^{\circ} \mathrm{C}$-warm-rolled specimen, which is much higher than $12.3 \mathrm{GPa} \cdot \%$ for the hot formed $22 \mathrm{MnB} 5$ steel and is also comparable to $38.3 \mathrm{GPa} \% \%$ for the annealed cold-rolled specimens.
\end{abstract}

Keywords: Medium Mn steel, warm rolling, microstructure, mechanical properties.

\section{Introduction}

In the past few years, the automotive industry has been searching for high/ultrahigh strength steels with good ductility to reduce the weight of vehicles while increasing its crashworthiness ${ }^{1,2}$. For example, the most commonly used boron steel (22MnB5) for hot forming exhibited an ultimate tensile strength (UTS) of $\sim 1,500 \mathrm{MPa}$ and quite low total elongation (TE) of $\sim 6 \%$ in the martensitic state ${ }^{3}$. Recent research mainly focused on improving the ductility of hot formed steels by either introducing a post-hot forming tempering treatment for $22 \mathrm{MnB} 5$ or developing an alternative class of hot formed steels such as a medium $\mathrm{Mn}$ steel ${ }^{4}$. In the latter case, UTS and TE in the ranges of 1330-1448 MPa and 16.7 25.3\% can be achieved after applying hot forming (HF) cycles at $700^{\circ} \mathrm{C}$ due to an additional TRIP effect and grain ultra-refinement of constituent phases (ferrite, austenite and martensite).

These new processing routes may offer a new opportunity for practical production of ultrahigh strength medium $\mathrm{Mn}$ steel, in view of the heavy springback during cold rolling ${ }^{5-8}$. As demonstrated in our preliminary work, dozens of passes in the cold rolling of medium $\mathrm{Mn}$ steel were required to reduce the sheet thickness from 4 to $1 \mathrm{~mm}$. Therefore, to reduce the number of process operations, it may be of interest to use an alternative route, i.e. only several-pass warm rolling. However, the potential of warm rolling of medium Mn steel has not yet been researched in detail so far.
In this study therefore, a novel Nb-Mo microalloyed medium Mn steel was subjected to a series of warm rolling tests at temperatures ranging from 600 to $720^{\circ} \mathrm{C}$, and compared with the commercial hot formed Mn steels and the conventional multi-stage thermo-mechanical process including hot rolling, cold rolling and intercritical annealing. The detailed microstructural evolution was investigated by scanning electron microscopy (SEM), electron backscatter diffraction (EBSD) and X-ray diffraction (XRD), etc., and uniaxial tensile tests were performed for optimizing the warm rolling temperature parameters.

\section{Experimental Procedure}

The experimental steel with composition of Fe-0.17C$6.6 \mathrm{Mn}-1.1 \mathrm{Al}-0.05 \mathrm{Nb}-0.22 \mathrm{Mo}$ (wt.\%) was prepared in a laboratory vacuum induction furnace. The equilibrium phase fraction as a function of temperature was determined from the TCFE5 database in Thermo-Calc ${ }^{\mathrm{TM}}$, as referred in our preliminary work ${ }^{6}$. Based on this work, the $A_{3}$ temperature was determined as $752{ }^{\circ} \mathrm{C}$, and the amount of austenite in equilibrium and retained at room temperature was also summarized in Table 1, together with the corresponding concentrations of $\mathrm{C}$ and $\mathrm{Mn}$ in austenite. The maximum amount of austenite retained at room temperature was approximately $38 \%$ after quenching from $660^{\circ} \mathrm{C}$. 
Table 1. The calculated phase fraction of austenite in equilibrium and retained at room temperature, together with the concentrations of $\mathrm{C}$ and Mn in austenite for each individual rolling temperature.

\begin{tabular}{|c|c|c|c|c|}
\hline$T$ & $V_{\gamma}$ in equilibrium & $\mathrm{C}$ in $\gamma$ & $\mathrm{Mn}$ in $\gamma$ & $V \gamma$ at room temp. $\%$ \\
\hline${ }^{\circ} \mathrm{C}$ & $\%$ & $\%$ & & $\%$ \\
\hline 630 & 45 & 0.42 & 12.5 & 20 \\
\hline 660 & 55 & 0.35 & 10.8 & 38 \\
\hline 690 & 70 & 0.29 & 9.8 & 23 \\
\hline
\end{tabular}

$T$-temperature; $V_{\gamma}$-the volume fraction of austenite.

The $50 \mathrm{Kg}$ ingot was forged after austenitization at $1200{ }^{\circ} \mathrm{C}$ for $1 \mathrm{~h}$, and cut into small plates with sectional area of $100 \mathrm{~mm} \times 100 \mathrm{~mm}$. Afterwards, rough hot rolling was carried out to produce the plates of $\sim 8.5 \mathrm{~mm}$ in thickness, followed by immediate quenching in oil. After machining the decarburized layers on both sides, small billets with a crosssection of $35 \mathrm{~mm} \times 65 \mathrm{~mm}$ and a thickness of $\sim 7 \mathrm{~mm}$ were heated to $850{ }^{\circ} \mathrm{C}$ for $20 \mathrm{~min}$, followed by air cooling to the desirable warm rolling temperature range from 630 to $690{ }^{\circ} \mathrm{C}$. The total rolling reduction was $\sim 80 \%$ with four passes. After each pass, reheating was required to ensure that the plate was soaked at the same temperature for $5 \mathrm{~min}$ before the next rolling pass.

Microstructural observations were performed using SEM, EBSD and XRD. Specimens for SEM and EBSD were prepared following the standard mechanical polishing. In the final step, samples were finished with a colloidal silica attack-polishing agent (OPS). SEM and EBSD were performed using a field-emission gun (FEG) SEM (ZeissSupra 55VP, Germany) integrated with an angle-selective backscattered (AsB) and EBSD detectors. A step size of 50 $\mathrm{nm}$ was selected for indexing and EBSD maps were acquired on the longitudinal section including the rolling and normal directions of samples. Post processing of EBSD data using the HKL Channel 5 software. The fraction of retained austenite was determined using XRD method with $\mathrm{Cu}-\mathrm{K} \alpha$ radiation following the ASTM method.

Tensile specimens with a gauge length of $5 \mathrm{~mm}$ and cross section of $6 \times(\sim 2)$ mm were machined from the WRed strips with tensile axis (TA) parallel to the rolling direction (RD). Uniaxial tensile tests were carried out on an INSTRON $596730 \mathrm{kN}$ machine at a constant strain rate of $5 \times 10^{-4} \mathrm{~s}^{-1}$. The engineering stress-strain curves were analyzed to determine the values of yield strength (YS), ultimate tensile strength (UTS) and total elongation to fracture (EI).

\section{Results and Analyses}

\subsection{Microstructural evolution}

The representative AsB maps of the WRed specimens at different temperatures are shown in Fig.1. It was found that rolling temperature had a strong effect on the final microstructures, which can be compared by their substructure development as well as martensitic transformation to austenite.
As the specimen was warm rolled at $630^{\circ} \mathrm{C}$, the lamella with indistinct grain boundaries were observed, as shown in Fig. 1. The mean spacing of lamella was approximately $100 \mathrm{~nm}$, which was thought to be associated with incomplete fragmentation of the deformed martensite by dislocation rearrangement during warm rolling 9,10 . As the rolling temperature rose to $660{ }^{\circ} \mathrm{C}$, the deformed ferrite with sharp grain boundaries (Fig. 1b) was observed, which was mainly attributed to the continuous absorption of dislocations into the low-angle boundaries. The degree of substructure development reflected the extent of recovery of the deformed martensite. With further raising the rolling temperature to $690{ }^{\circ} \mathrm{C}$, the martensite packets in some localized regions were observed, which originated from the partial martensitic transformation from austenite upon cooling due to a loss of thermal stability of retained austenite (Fig. 1c).

For a detailed analysis on the influence of warm rolling temperature on the final microstructural parameters, EBSD mapping was performed as well. The representative phase distribution and grain boundary misorientation maps as a function of rolling temperature are shown in Fig. 2. The phase maps clearly show the change in the fraction of retained austenite $\left(V_{\gamma}\right)$ with rolling temperature, indicating that the $V_{\gamma}$ value first increased and then decreased with increasing rolling temperatures from 630 to $690{ }^{\circ} \mathrm{C}$, which mainly depended on the fraction of austenite in equilibrium and the change in alloying concentrations (e.g. C and Mn elements) in austenite with temperature. This experimental result is in accordance with the abovepredicted one, i.e. the maximum austenite fraction was obtained after warm rolling at $\sim 660{ }^{\circ} \mathrm{C}$. Considering the accuracy of EBSD measurement, the amount of retained austenite was further determined and analyzed based on the following XRD data.

According to quantitative EBSD analysis, a relatively higher fraction of BCC phase (ferrite or martensite) with low angle grain boundaries (LAGBs) $(\sim 52.9 \%)$ was found in the $630^{\circ} \mathrm{C}$-WRed specimen (as marked by the black line in Fig. 3a), which is consistent with the above-mentioned incomplete recrystallization behavior. In comparison, the fraction of bcc phase with LAGBs dropped significantly to $\sim 38.5 \%$ in the $660^{\circ} \mathrm{C}$-WRed specimen (as marked by the red line in Fig. 3a), which was thought to be associated with further recrystallization of the deformed bcc phase. 
With further increasing rolling temperature to $690{ }^{\circ} \mathrm{C}$, the fraction of bcc phase with LAGBs reached $\sim 36.8 \%$ (as marked by the blue line in Fig. 3a), which was closely related to the formation of a large fraction of thermal martensite upon cooling. In contrast, as the warm rolling increased from 630 to $660{ }^{\circ} \mathrm{C}$, the fraction of $\mathrm{BCC}$ phase with LAGBs dropped by $\sim 10 \%$, implying the occurrence of dynamic globalization during reverse transformation from the deformed martensite to austenite.

In order to compare the volume fraction of retained austenite at different rolling temperatures, a quantitative XRD analysis was performed. Fig. 4 shows the XRD patterns of these WRed specimens at three different rolling temperatures. The volume fraction of retained austenite was calculated from the integrated

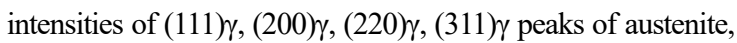
and those of (110) $\alpha,(200) \alpha,(211) \alpha,(220) \alpha$ peaks of ferrite.
The volume fraction of retained austenite was estimated by the following equation:

$$
V_{\gamma}=\left(I_{\gamma} / R_{\gamma}\right) /\left[\left(I_{\gamma} / R_{\gamma}\right)+\left(I_{\alpha} / I_{\alpha}\right)\right]
$$

where is the volume fraction of retained austenite, is a theoretical parameter that is proportional to the theoretical integral strength; are integrated intensity per angular diffraction peak (hkl) in the $\alpha$-phase or the $\gamma$-phase, respectively,

Similar to EBSD data, the amount of retained austenite first increased and then decreased with increasing rolling temperature from 630 to $690{ }^{\circ} \mathrm{C}$. The 630 -WRed specimen contained $\sim 16.0 \%$ retained austenite, which is lower than the value $(\sim 21 \%)$ in the 660 -WRed specimen. After warm rolling at $690{ }^{\circ} \mathrm{C}$. The amount of retained austenite slightly dropped to $\sim 18 \%$.
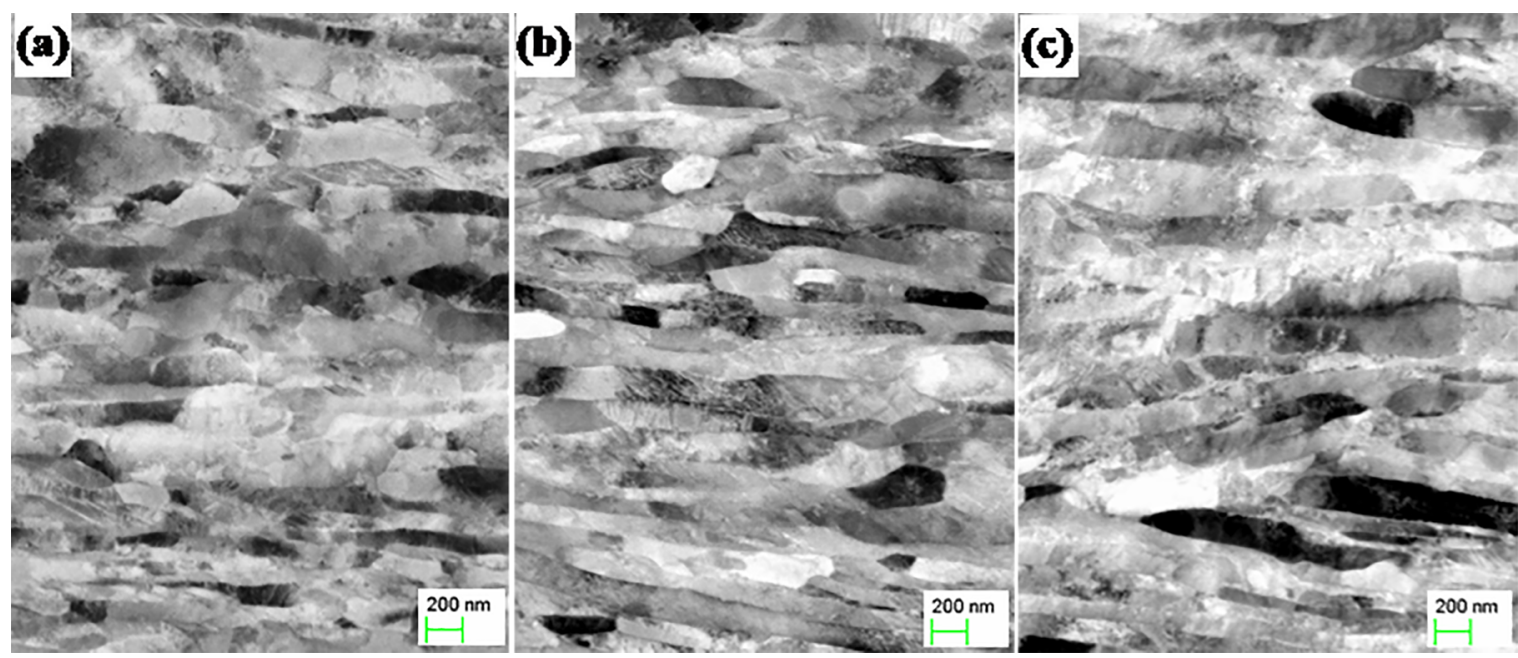

Figure 1. AsB maps of a $0.17 \mathrm{C}-6.6 \mathrm{Mn}-1.1 \mathrm{Al}-0.05 \mathrm{Nb}-0.22 \mathrm{Mo}$ steel processed by warm rolling at various temperatures: (a) $630{ }^{\circ} \mathrm{C}$, (b) $660^{\circ} \mathrm{C}$ and (c) $690^{\circ} \mathrm{C}$.
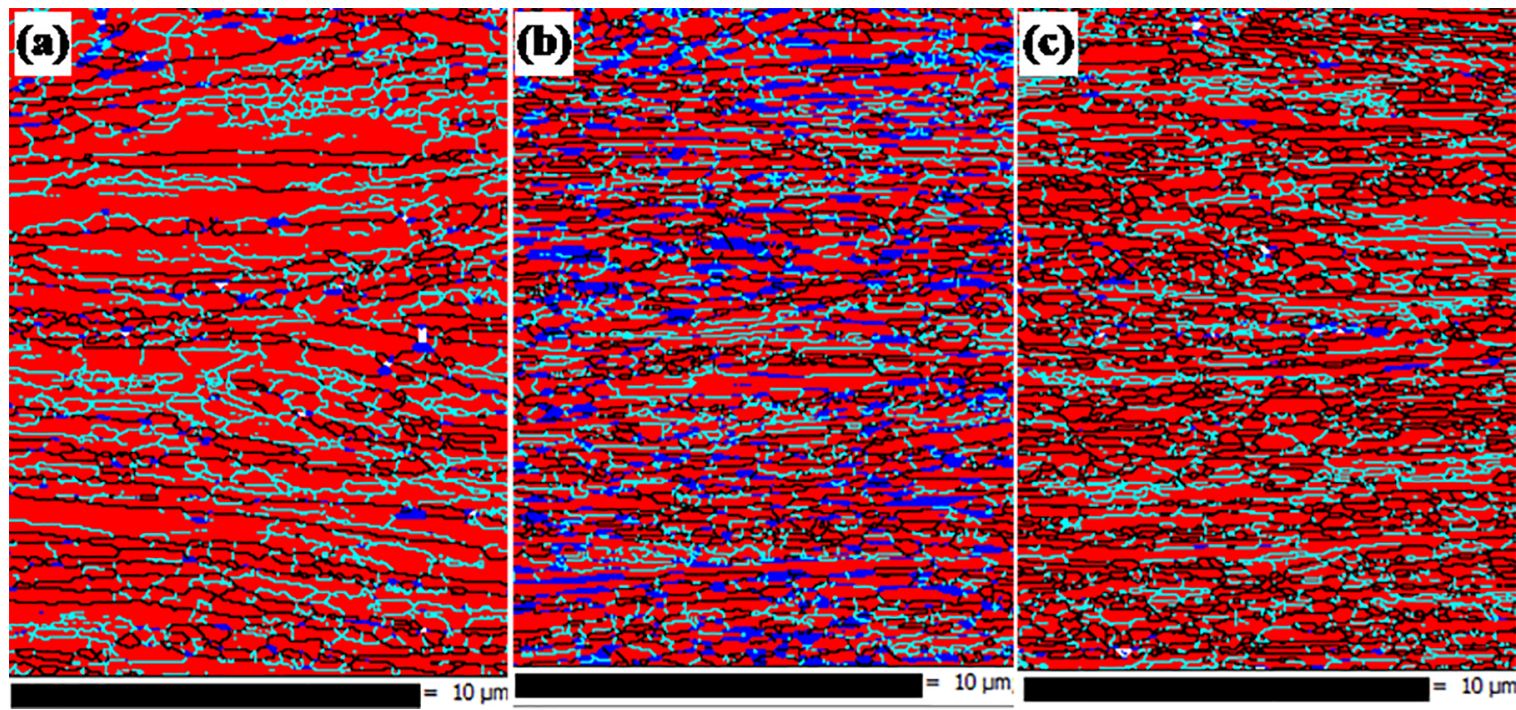

Figure 2. Phase distribution and grain boundaries of a $0.17 \mathrm{C}-6.6 \mathrm{Mn}-1.1 \mathrm{Al}-0.05 \mathrm{Nb}-0.22 \mathrm{Mo}$ steel processed by warm rolling at various temperatures: (a) $630{ }^{\circ} \mathrm{C}$; (b) $660^{\circ} \mathrm{C}$ and (c) $690^{\circ} \mathrm{C}$. BCC-red; FCC-blue; HAGBs $\left(>15^{\circ}\right)$-solid black line; LAGBs $\left(2 \sim 15^{\circ}\right)$-solid green line. 

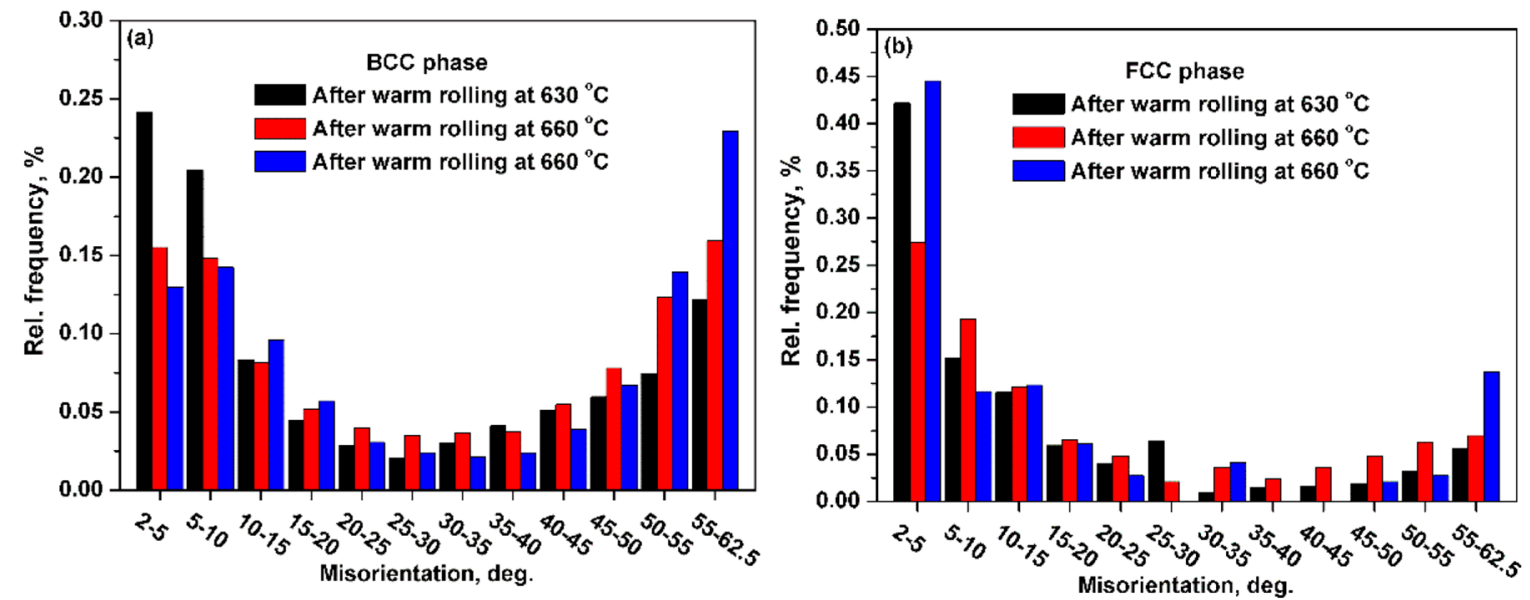

Figure 3. Grain boundaries misorientation distribution profiles for both $\mathrm{BCC}(\mathrm{a})$ and $\mathrm{FCC}(\mathrm{b})$ phases in a $0.17 \mathrm{C}-6.6 \mathrm{Mn}-1.1 \mathrm{Al}-0.05 \mathrm{Nb}-0.22 \mathrm{Mo}$ steel processed by warm rolling at 630,660 and $690^{\circ} \mathrm{C}$.

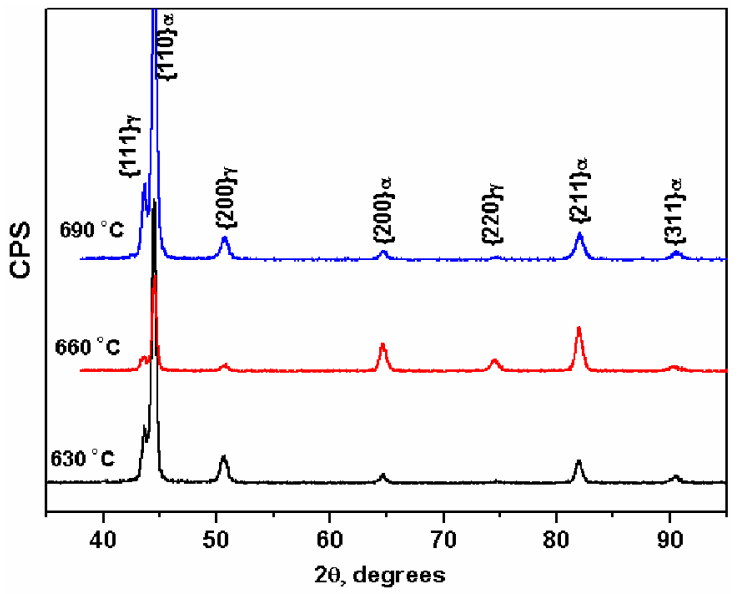

Figure 4. X-ray diffraction patterns of a $0.17 \mathrm{C}-6.6 \mathrm{Mn}-1.1 \mathrm{Al}-$ $0.05 \mathrm{Nb}-0.22 \mathrm{Mo}$ steel processed by warm rolling at temperatures ranging from 630 to $690^{\circ} \mathrm{C}$.

\subsection{Tensile properties}

The tensile engineering stress-strain curves of all WRed specimens are shown in Fig.5, illustrating a significant dependence of tensile properties on warm rolling temperature. As warm rolling was performed at $630{ }^{\circ} \mathrm{C}$, the specimen exhibited both high yield strength (YS $>1100 \mathrm{MPa}$ ) and ultimate tensile strength (UTS $>1100 \mathrm{MPa}$ ), but the yield ratio was quite high (YS/UTS $>0.9$ ), due to the absence of work hardening caused by the ultrafine BCC structure mixed with the retained austenite with relatively high mechanical stability. After warm rolling at $690{ }^{\circ} \mathrm{C}$, the mechanical stability of retained austenite was so low that it quickly transformed to martensite at low strain levels, corresponding to continuous yield behavior and extremely high initial work hardening rate.
As a result, the specimen exhibited extremely high UTS of $\sim 1,600 \mathrm{MPa}$ and limited tensile ductility (TE) of $\sim 16 \%$. Surprisingly, the $660^{\circ} \mathrm{C}$-WRed tensile specimen exhibited an obvious yield point extension due to the localized deformation, followed by a sustained work hardening behavior occurring over the large strain range from $\sim 5.5 \%$ to $\sim 22.5 \%$. Thus, an excellent combination of both high UTS $(\sim 1420 \mathrm{MPa})$ and good ductility $(\sim 22.5 \%)$ was achieved in this case. In comparison, a better combination of UTS $(>1,420 \sim 1,600 \mathrm{MPa})$ and high ductility $(>16 \sim 22.5 \%)$ was achieved after warm rolling above $660^{\circ} \mathrm{C}$ without any further annealing. The product of UTS and TE ranged from 25.6 to $32.0 \mathrm{GPa} \cdot \%$, which is much higher than $12.3 \mathrm{GPa} \cdot \%$ for the HF $22 \mathrm{MnB} 5$ steel $^{4}$, and is also comparable to $38.3 \mathrm{GPa} \cdot \%$ for the annealed CR specimen ${ }^{7}$.

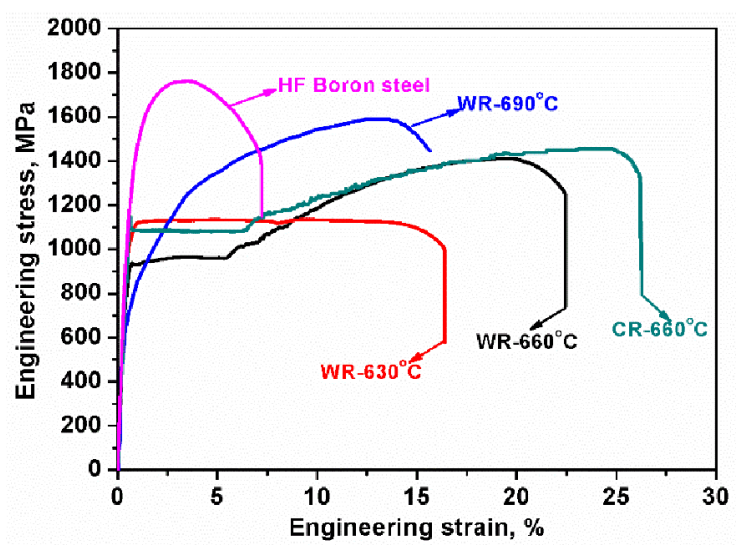

Figure 5. Engineering stress-strain curves of a $0.17 \mathrm{C}-6.6 \mathrm{Mn}-1.1 \mathrm{Al}-$ $0.05 \mathrm{Nb}-0.22 \mathrm{Mo}$ steel processed by warm rolling at temperatures ranging from 630 to $690^{\circ} \mathrm{C}$, together with those of HFed 22MnB5 steel [4] and the CRed specimen after annealing at $660^{\circ} \mathrm{C}$ for $30 \mathrm{~min}$ [7]. 


\section{Discussion}

Many researches have shown that the overall mechanical properties of medium Mn steel are proportional to the volume fraction of retained austenite partly due to the TRIP effect ${ }^{9}$. The present work however, shows that the $V_{\gamma}$ ranged from $\sim 16 \%$ to $\sim 21 \%$, implying no significant difference in the fraction of retained austenite, regardless of warm rolling temperature. Therefore, our medium Mn steel exhibited a remarkable change in mechanical response among these warm-rolled specimens at three various temperatures, which reflected the rolling-temperature-dependence of the TRIP effect or the mechanical stability of the retained austenite.

It is known that there exists a direct relationship between work hardening rate and the rate of martensitic transformation in metastable austenitic stainless steels ${ }^{6,10,11}$. The higher is the transformation rate, the higher is the work hardening rate. Similarly, the ductility of medium Mn steel can be also improved by the TRIP effect, because the high work hardening caused by TRIP can delay the necking behavior, and can also aid in strain accommodation ${ }^{12}$. Thus, it may be reasonable to evaluate the martensitic transformation behavior corresponding to the mechanical stability of the retained austenite by analyzing the flow behavior. As described in Section 3.1, the $630^{\circ} \mathrm{C}$-WRed structure experienced incomplete fragmentation due to quite slow diffusion rate of $\mathrm{C}$ and $\mathrm{Mn}$, resulting in the ultrafine ferrite + martensite + retained austenite duplex structure with a high fraction of LAGBs. Meanwhile, the retained austenite exhibited so high mechanical stability that it hardly transformed to martensite upon tensile straining. In this case, this deformation behavior of the $630^{\circ} \mathrm{C}$-WRed specimen was characterized by almost no work hardening, which is similar to what was observed in the UFG ferrite structure produced by severe plastic deformation (SPD) or dynamic transformation. In contrast, as the rolling temperature was raised to $690^{\circ} \mathrm{C}$, the as-rolled microstructure was composed of ferrite and retained austenite, together with a large fraction of thermal martensite. Also, the mechanical stability of austenite was reduced due to the decreased concentrations of $\mathrm{C}$ and $\mathrm{Mn}$ in austenite and the growth of austenite grains. Thus, the TRIP effect was complete at quite low strain levels, resulting in high UTS but limited ductility. However, partial dynamic globalization of the deformed martensite occurred during warm rolling at $660^{\circ} \mathrm{C}$, i.e. a heterogeneous lamellar and granular $(\alpha+\gamma)$ duplex structure was formed in this case. The microstructural-level inhomogeneity severs as the initial imperfection, triggering strain partitioning and finally shear band localization upon tensile straining ${ }^{13}$. Thus, it can be inferred that the excellent properties of the $660{ }^{\circ} \mathrm{C}$-WRed specimen was mainly attributed to the combined effects of a heterogeneous duplex structure, together with the sustained TRIP effect occurring during plastic deformation.
In summary, the present study demonstrates that warm rolling without any subsequent inter-critical annealing can not only improve the mechanical properties of medium $\mathrm{Mn}$ steels, but also the surface quality of the final steel plates. The combined effects of rolling temperature on the overall properties of medium Mn steel resulted from the following aspects, i.e. phase constituent, the fraction of retained austenite and the mechanical stability of retained austenite ${ }^{6-8,14,15}$. In particular, the multiple $\mathrm{Nb}$-Mo microalloying plus warm rolling may be a promising method for the development of a new generation of advanced high-strength medium Mn steel.

\section{Conclusions}

This work investigated the influence of warm rolling temperature on the microstructure and mechanical properties of Nb-Mo micraolloyed medium Mn steel. The following conclusions could be drawn:

(1) The WRed medium Mn steel exhibited the lamellar multiphase microstructure, and the microstructural evolution strongly depended on rolling temperature. With increasing warm rolling temperature from 630 to $660{ }^{\circ} \mathrm{C}$. The fraction of bcc phase with LAGBs significantly dropped, due to dynamic globalization of the deformed microstructure. After warm rolling at $690 \mathrm{oC}$, the decreased fraction of LAGBs was mainly associated with the formation of martensitic transformation upon cooling.

(2) A better combination of UTS and TE $(\sim 32.0 \mathrm{GPa} \cdot \%)$ was achieved in the $660^{\circ} \mathrm{C}$ - warm-rolled specimen, which is much higher than $12.3 \mathrm{GPa} \cdot \%$ for the hot formed $22 \mathrm{MnB} 5$ steel, and is also comparable to that of the conventional annealed cold-rolled medium Mn steel.

(3) The combined effects of warm rolling temperature on the overall properties of medium Mn steels were mainly attributed to the phase constituent, the fraction of retained austenite and its mechanical stability.

\section{Acknowledgements}

The authors gratefully acknowledge the financial support of Northeastern University College Students' Practice and Training Program (Grant No.180099), Fundamental Research Funding of the Central Universities, China (Grant No.N160204001) and Henan Provincial Science and Technology Cooperation Project, China (No.182106000016) and Natural Science Foundation of China (Grant No. 51401050 \& No.U1760205). 


\section{References}

1. Suh DW, Kim SJ. Medium Mn transformation-induced plasticity steels: Recent progress and challenges. Scripta Materialia. 2017;126:63-67.

2. Hu B, Luo H, Yang F, Dong H. Recent progress in medium-Mn steels made with new designing strategies, a review. Journal of Materials Science and Technology. 2017;33(12):1457-1464.

3. Karbasian H, Tekkayam AE. A review on hot stamping. Journal of Materials Science and Technology. 2010;210(15):2103-2118.

4. Rana R, Garson CH, Speer JG. Proceedings of 5th International Conference on Hot Sheet Metal Forming of High-performance Steel. Canada: Inhaltsverzeichnis; 2015.

5. Ding R, Dai ZB, Huang MX, Yang ZG, Zhang C, Chen H. Effect of pre-existed austenite on austenite reversion and mechanical behavior of an Fe-0.2C-8Mn-2Al medium Mn steel. Acta Materialia. 2018;147:59-69.

6. Cai MH, Li Z, Chao Q, Hodgson PD. A novel Mo and Nb microalloyed medium Mn TRIP steel with maximal ultimate strength and moderate ductility. Metallurgical and Materials Transactions: A. 2014;45:5624-5634.

7. Cai MH, Zhu WJ, Stanford N, Pan LB, Chao Q, Hodgson PD. Dependence of deformation behavior on grain size and strain rate in an ultrahigh strength-ductile Mn-based TRIP alloy. Materials Science and Engineering: A. 2016;653:35-42.
8. Pan HJ, Cai MH, Ding H, Huang HS, Zhu B, Wang YL, et al. Materials Design. 2017;134:352-360.

9. Suh DW, Kim SJ. Medium Mn transformation-induced plasticity steels: Recent progress and challenges. Scripta Materialia. 2017;126:63-67.

10. Herrera C, Ponge D, Raabe D. Design of a novel Mn-based $1 \mathrm{GPa}$ duplex stainless TRIP steel with $60 \%$ ductility by a reduction of austenite stability. Acta Materialia. 2011;59:4653-4664

11. Beladi H, Cizek P, Hodgson PD. Dynamic recrystallization of austenite in Ni-30 Pct Fe model alloy: Microstructure and texture evolution. Metallurgical and Materials Transactions: A. 2009;40:1175-1189.

12. Lee YK, Han J. Current opinion in medium manganese steel. Materials Science and Technology. 2015;31(7):843-856.

13. Choi KS, Soulami A, Liu WN, Sun XW. Influence of various material design parameters on deformation behaviors of TRIP steels. Computational Materials Science. 2010;50(2):720-730.

14. Suh DW, Park SJ, Lee TH, Oh CS, Kim SJ. Influence of Al on the microstructural evolution and mechanical behavior of low-carbon, manganese transformation-induced-plasticity steel. Metallurgical and Materials Transactions: A. 2010;41(2):397-408.

15. Luo HW, Shi J, Wang C, Cao WQ, Sun XJ, Dong H. Acta Materialia. 2011;59:4002-4014. 